\title{
Evaluation of Vaginal Fluid Urea and Creatinine as Biomarkers of Preterm Premature Rupture of Membranes
}

\author{
Khaled M. slama, Ahmed Salah El din, Aymen S. Elgohary, Basma M. Mostafa
}

\begin{abstract}
Email:
basma_dr2016@hotmail.com
\end{abstract}

Received : 26 September 2020

Accepted: 22 November 2020

\section{Abstract:}

Background: PROMs occurs in $10 \%$ of all term pregnancies and about 2- $4 \%$ of preterm pregnancies and is associated with complications such as infection and preterm birth. Vaginal fluid urea and creatinine levels may be helpful in the diagnosis of PROM. Objectives: To evaluate the reliability of vaginal washing fluid urea and creatinine as biomarkers for diagnosis of preterm PROM. Subjects and Methods:A prospective case control study was conducted at the Obstetrics and Gynecology Department; Benha University Hospital during the period from September 2018 to September 2019. The study included 100 cases: 50 inpatient cases with preterm PROM and 50 cases from those attending outpatient clinics for routine antenatal care. All patients underwent speculum examination, nitrazine paper test, and U/S. Results: The creatinine levels were $0.35 \pm 0.12 \mathrm{mg} / \mathrm{dl}$ and $0.16 \pm 0.08 \mathrm{mg} / \mathrm{dl}$ in confirmed cases and controls, respectively. The urea levels were $6.5 \pm 2.48 \mathrm{mg} / \mathrm{dl}$ and $3.4 \pm 1.68$ $\mathrm{mg} / \mathrm{dl}$ in confirmed cases and controls, respectively. There was a

highly significant difference regarding creatinine level and urea level $(\mathrm{P}<0.001)$. Sensitivity, specificity, PPV and NPV for creatinine level were 100\%, 84\%, 86,2\% and 100\%, respectively. Sensitivity, specificity, PPV and NPV, for urea level was 100\%, 80\%, $83.3 \%$ and 100\%, respectively, with a cut-off value of $0.2 \mathrm{mg} / \mathrm{dl}$ for creatinine level and $3 \mathrm{mg} / \mathrm{dl}$ for urea level. Conclusions: Detection of vaginal fluid urea and creatinine to diagnose PROM is a simple, reliable and rapid test with high sensitivity, specificity, PPV, NPV.

Keywords: pregnant women, premature rupture of membrane, urea and creatinine 



\section{Introduction}

Premature rupture of membranes (PROM) refers to rupture of the fetal membranes prior to the onset of labor. It occurs in $10 \%$ of all term pregnancies and about 2- $4 \%$ of preterm pregnancies and is associated with complications such as infection and preterm birth ${ }^{1}$. The risk of fetal infection in patients with PROM is $5 \%$ and reaches $20 \%$ in those with chorioamnionitis. ${ }^{2}$

Accurate history, clinical examination and specialized tests are the hallmark for diagnosing PROM. Failure to identify patient or false positive diagnosis of PROM may lead to inappropriate management and serious maternal and neonatal complications or unnecessary obstetric interventions ${ }^{3}$.

Diagnosis of PROM can be made by (1) Observation of clear amniotic fluid flow or accumulation of fluid at posterior fornix with a sterile speculum, (2) Observation of transition from yellow to blue with $\mathrm{pH}$ indicator paper due to basic amniotic fluid flow (nitrazine test) and/or 3) Detection of palm leaf-pattern in dried amniotic fluid with microscopic method (fern test) ${ }^{4}$.

However, these conventional methods are associated with drawbacks. History is reliable in $10 \%$ to $50 \%$ of cases; speculum examination of fluid leakage from the cervix was associated with $12 \%-30 \%$ false negative results. Nitrazine test was associated with false positive results in $28 \%$ and false negative in $12 \%$ of cases due to contamination by urine (alkaline), blood or meconium, antibiotics, vaginal and cervical infections. Fern test was also associated with $13-30 \%$ false negative and $5-30 \%$ false positive results 5 .

Assessment of amniotic fluid volume by ultrasound examination is not a reliable test to evaluate membrane rupture because it cannot differentiate PROM from other causes of oligohydramnios ${ }^{6}$.

Intra amniotic dye injection and observation for fluid passage transvaginal was designated an "unequivocal" diagnostic method for confirmation of membrane rupture, but this invasive test carries increased maternal and fetal risk. ${ }^{7}$

The Amnisure ROM test is another new test that is easy, fast, minimally invasive and with high sensitivity and specificity. However, Amnisure is not available in many centers and it is expensive. 8, 9 Many biochemical diagnostic modalities for PROM have been described, like 
measurement of vaginal $\mathrm{pH}$, alpha fetoprotein (AFP), insulin growth factor binding protein-1(IGFBP-1), fetal fibronectin tests, human chorionic gonadotropin (HCG), prolactin, urea, and creatinine ${ }^{10}$.

The justification of assessing these markers is their high concentrations in amniotic fluid compared with normal vaginal secretions. However, despite the improved diagnostic potential of these markers, they have not become popular due to their complexity and high cost. ${ }^{11}$

Recently, the focus has been on urea and creatinine in cervico-vaginal discharge. It is based on the concept that fetal urine is the prime component of amniotic fluid in the second half of pregnancy. The fetus starts excreting urine into the amniotic fluid at 8th to 11th week of gestation. As there is no need for extra equipment and reagent, introduction of this method into routine use seem to be feasible and practical.

\section{Subjects and methods:}

A prospective case control study was conducted at the Obstetrics and Gynecology Department, Benha University Hospital during the period from September 2018 to September 2019 and approved by the Local
Ethics Committee of the Department. Informed consent was obtained from all participants prior to commencing the study.

The study included 100 cases: 50 cases admitted to the obstetrics and gynecology department with preterm PROM and 50 cases from those attending outpatient clinics for routine antenatal care.

\section{Inclusion criteria:}

A total of 100 singleton pregnant women with GA 24-34 weeks as confirmed by LMP and/or first trimester sonography) are included in this study.

\section{Exclusion criteria:}

Women with medical disorders (renal or liver impairment, hypertensive disorder, diabetes and other complications),women with preterm labor, evidence of chorioamnionitis, women with vaginal spotting/ bleeding or meconium in vaginal fluid leak, congenital fetal malformations (particularly renal or urinary tract anomalies), intrauterine fetal death, evidence of vaginal infection, use of vaginal drugs or antiseptic or recent intercourse.

Creatinine level in PROM group was 0.35 $\pm 0.12 \mathrm{mg} / \mathrm{dl}$ and in the control group was $0.16 \pm 0.08 \mathrm{mg} / \mathrm{dl}$. The sample size had been 
calculated at $95 \%$ confidence interval and power $80 \%$. A total of 100 cases were included in the study. The sample was distributed into 50 cases controls, 50 cases confirmed PROM. The cases were then divided according to amniotic fluid and nitrazine paper result, into the following:

- Group I (50 cases): confirmed PROM cases by amniotic fluid pooling and positive nitrazine paper test result

- Group II (50 cases): control group: pregnant women without any complaint or complication with negative amniotic fluid pooling and negative nitrazine paper test result.

After explaining about the aim of this study and procedure to the patients and obtaining informed consent, the patients were included. A thorough history was taken, and physical examination was done. All patients underwent a sterile speculum examination and amniotic fluid pooling with or without Valsalva maneuver. Nitrazine paper test was done for all cases as a screening test for amniotic fluid leak and an abdominal ultrasonography for GA, AFI, fetal viability, placental site, and congenital anomalies, routine investigations: including complete blood picture, blood group and $\mathrm{Rh}, \mathrm{C}$ reactive protein, random blood sugar and mid-stream urine analysis and CTG.

Vaginal fluid washing was done through flushing of $5 \mathrm{ml}$ saline in the posterior vaginal fornix, and then all the fluid was aspirated from posterior fornix for detection of urea and creatinine levels. The collected samples were sent to the laboratory for assay of urea and creatinine concentrations. The colorimetric method for urea assay is based on enzymatic urease reaction.The colorimetric method for creatinine assay is based on the reaction between creatinine in alkaline solution with picric acid (Jaffé colorimetric method).

\section{Statistical Methods}

Quantitative data are presented as mean \pm SD. Quantitative and qualitative data were analyzed using independent t test, and Chisquare test, respectively. The data were analyzed using Statistical Package for Social Sciences (SPSS version 25(IBM, Armonk, New York, USA). A $\mathrm{p}$ value of less than 0.05 was considered statistically significant.

\section{Results}

There was no statistically significant difference between both groups regarding, maternal age, weight, parity and gestational 
age $(\mathrm{P}=0.2,0.1,0.6$ and 0.6 respectively)

(Table 1).

There was a statistically significant difference between the 2 groups regarding vaginal fluid creatinine. The mean value of creatinine was higher in the PROM group than in the control group $(0.35 \pm 0.12 \mathrm{mg} / \mathrm{dL}$ vs. $0.16 \pm 0.08 \mathrm{mg} / \mathrm{dL}, \mathrm{P}<0.001)$. There was a statistically significant difference between the 2 groups regarding vaginal fluid urea. The mean value of urea was higher in the PROM group than in the control group $(6.5$ $\pm 2.48 \mathrm{mg} / \mathrm{dL}$ vs. $3.4 \pm 1.68 \mathrm{mg} / \mathrm{dL}, \mathrm{P}<$ 0.001) (Table 2).

There was a highly significant difference regarding AFI, Mean AFI $\mathrm{SD}$ was significantly lower in PROM group (8.75 \pm $1.14 \mathrm{~cm}$ ) compared to control group (11.15 $\pm 1.86 \mathrm{~cm}), \mathrm{P}<0.001($ Table 3 )

Mean vaginal fluid urea was significantly higher in patients with gestational age $\geq 33$ weeks ( $8 \mathrm{mg} / \mathrm{dl}$ ) compared to those with gestational age $<33$ weeks $(5 \mathrm{mg} / \mathrm{dl}), \mathrm{P}$ $<0.001$.

Mean vaginal fluid creatinine was significantly higher in patients with gestational age $\geq 33$ weeks $(0.42 \mathrm{mg} / \mathrm{dl})$ compared to those with gestational age $<33$ weeks $(0.28 \mathrm{mg} / \mathrm{dl}), \mathrm{P}<0.001$.

Mean AFI was significantly higher in patients with gestational age <33 weeks (9.1) compared to those with gestational age $\geq 33$ weeks (8.4), $\mathrm{P}=0.029$. (table 4, figure1).

Sensitivity, specificity, positive predictive value and negative predictive value for creatinine level as a screening test for PROM were $100 \%, 84 \%, 86.2 \%$ and $100 \%$, respectively. Sensitivity, specificity, positive predictive value and negative predictive value, for urea level as a screening test for PROM were $100 \%, 80 \%, 83,3 \%$ and $100 \%$, respectively, with a cut-off value of 0.2 $\mathrm{mg} / \mathrm{dl}$ for creatinine level and $3 \mathrm{mg} / \mathrm{dl}$ for urea level (table 5).

Sensitivity, specificity, PPV, and NPV for AFI as a screening test for PROM were $100 \%, 60 \%, 71.4 \%$ and $100 \%$, respectively (table 6,figure3).

ROC analysis was done for vaginal fluid urea and creatinine in diagnosis of PROM. It revealed significant Area Under Curve (AUC) of $0.895 \quad(\mathrm{P}<0.001)$ and 0.937 $(\mathrm{P}<0.001)$ for urea and creatinine respectively (table5, figure2). 
Benha medical journal Vol. 37, Special issue (surgery), 2020

Table 1 : Demographiccharacteristics of the studied groups

\begin{tabular}{|c|c|c|c|c|}
\hline & & $\begin{array}{l}\text { PROM group } \\
(\mathrm{n}=50)\end{array}$ & $\begin{array}{l}\text { Control group } \\
(\mathrm{n}=50)\end{array}$ & $\mathrm{P}$ value \\
\hline Age (years) & Mean \pm SD & $30 \pm 2$ & $30 \pm 1.5$ & 0.2 \\
\hline Weight (kg) & Mean \pm SD & $82 \pm 8$ & $80 \pm 6$ & 0.1 \\
\hline Gestational age (weeks) & Mean \pm SD & $32 \pm 1.9$ & $32 \pm 1.8$ & 0.6 \\
\hline \multicolumn{5}{|l|}{ Parity } \\
\hline Primigravida & No $(\%)$ & $14(28)$ & $11(22)$ & 0.6 \\
\hline Multipara & No $(\%)$ & $36(32)$ & $39(40)$ & \\
\hline
\end{tabular}

Table 2 : Vaginal fluid urea and creatinine level in both groups

\begin{tabular}{|c|c|c|c|c|}
\hline & & $\begin{array}{l}\text { PROM group } \\
(\mathbf{n}=\mathbf{5 0})\end{array}$ & $\begin{array}{l}\text { Control group } \\
(\mathbf{n}=\mathbf{5 0})\end{array}$ & $P$ value \\
\hline Urea (mg/dl) & Mean \pm SD & $6.5 \pm 2.48$ & $3.4 \pm 1.68$ & $<0.001$ \\
\hline $\begin{array}{l}\text { Creatinine } \\
(\mathrm{mg} / \mathrm{dl})\end{array}$ & Mean \pm SD & $0.35 \pm 0.12$ & $0.16 \pm 0.08$ & $<0.001<0,001$ \\
\hline
\end{tabular}

Table 3 : Amniotic fluid index in both groups

\begin{tabular}{|c|c|c|c|c|}
\hline & & $\begin{array}{l}\text { PROM group } \\
(\mathbf{n}=50)\end{array}$ & $\begin{array}{l}\text { Control group } \\
(\mathbf{n}=\mathbf{5 0})\end{array}$ & P value \\
\hline AFI & Mean \pm SD & $8.75 \pm 1.14$ & $11.15 \pm 1.86$ & $<0.001$ \\
\hline
\end{tabular}

AFI = Amniotic fluid index 
Table 4 : Correlation of vaginal fluid urea, creatinine and AFI to gestational age in PROM group

\begin{tabular}{llllll}
\hline & GA $<33$ & \multicolumn{5}{c}{ GA $\geq \mathbf{3 3}$} \\
& Mean & \pm SD & Mean & \pm SD & P value \\
\hline Urea (mg/dl) & 5 & 1.29 & 8 & 2.5 & $<0.001$ \\
Creatinine (mg/d) & 0.28 & 0.04 & 0.42 & 0.12 & $<0.001$ \\
AFI & 9.1 & 0.68 & 8.4 & 1.38 & 0.029 \\
\hline
\end{tabular}

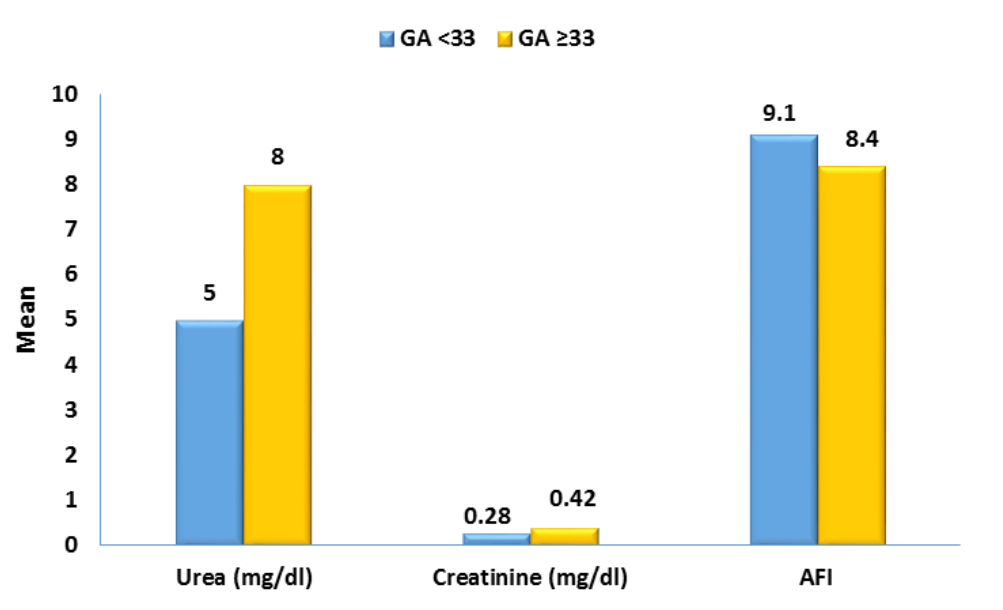

Figure 1: Vaginal fluid urea \& creatinine and AFI according to gestational age

Table 5: ROC characteristics of vaginal fluid urea and creatinine

\begin{tabular}{lll}
\hline & Urea & Creatinine \\
AUC & 0.895 & 0.937 \\
\hline $\mathbf{9 5 \%}$ CI & $0.830-0.960$ & $0.890-0.984$ \\
Best cutoff & 3 & 0.2 \\
Sensitivity & $100 \%$ & $100 \%$ \\
Specificity & $80 \%$ & $84 \%$ \\
PPV & $83.3 \%$ & $86.2 \%$ \\
NPV & $100 \%$ & $100 \%$ \\
$\mathbf{P}_{\mathbf{1}}$ & $<0.001$ & $<0.001$ \\
$\mathbf{P}_{\mathbf{2}}$ & 0.303 & \\
\hline
\end{tabular}


Benha medical journal Vol. 37, Special issue (surgery), 2020

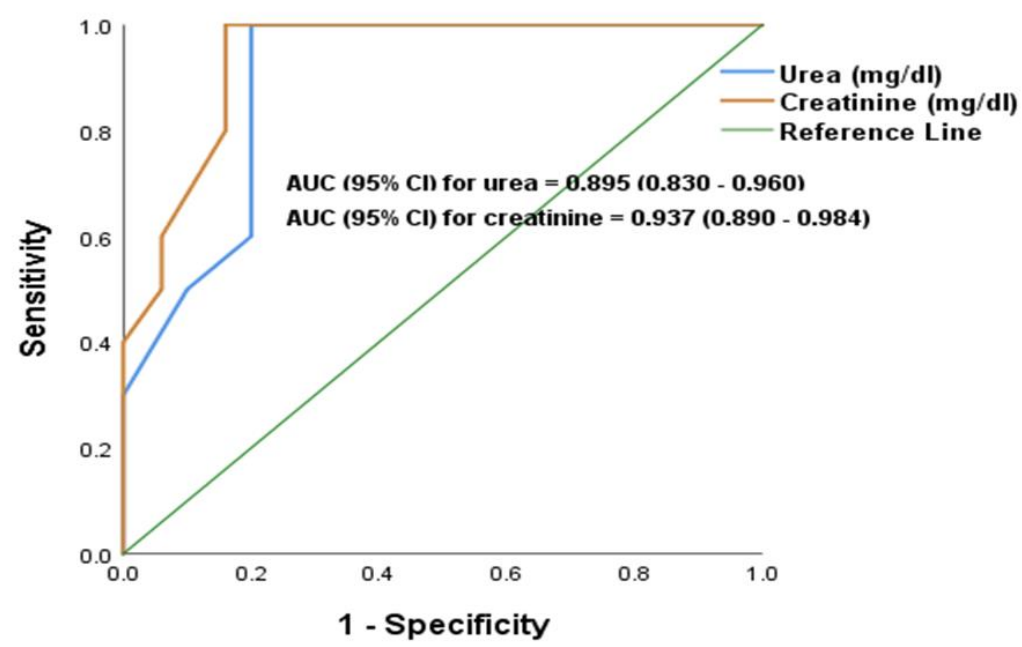

Figure 2: ROC analysis for vaginal fluid urea and creatinine

Table 6 : ROC characteristics of AFI

\begin{tabular}{ll}
\hline \multicolumn{2}{l}{ ROC characteristics } \\
\hline AUC & 0.870 \\
$\mathbf{9 5 \%}$ CI & $0.803-0.937$ \\
Best cutoff & $\leq 10$ \\
Sensitivity & $100 \%$ \\
Specificity & $60 \%$ \\
PPV & $71.4 \%$ \\
NPV & 100 \\
$\mathbf{P}$ & $<0.001$ \\
\hline
\end{tabular}

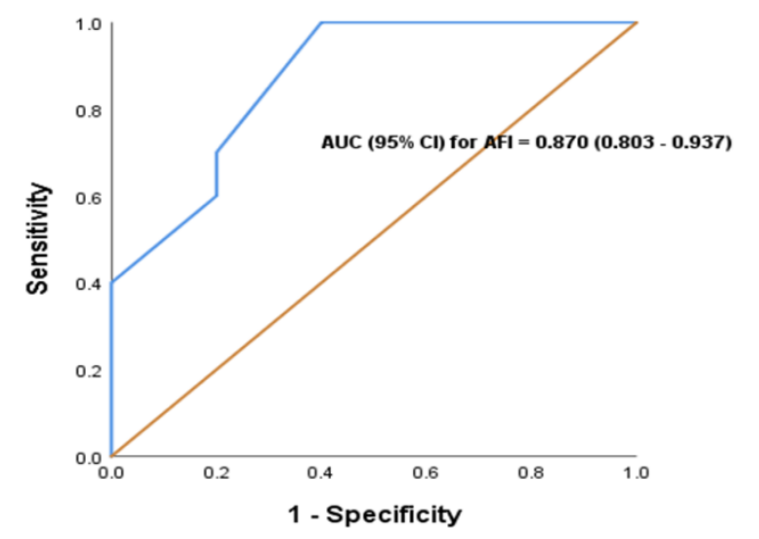

Figure 3: ROC analysis of AFI in diagnosing PROM 


\section{Discussion}

This study was conducted to evaluate the reliability of vaginal washing fluid urea and creatinine in diagnosis of PPROM.

In the present study, the mean AFI was significantly lower in PROM group (8.75 \pm $1.14 \mathrm{~cm}$ ) compared to control group (11.15 $\pm 1.86 \mathrm{~cm}), \mathrm{P}<0.001$. ROC analysis and characteristics showed that the best cut-off value of $\mathrm{AFI}$ is $\leq 10 \mathrm{~cm}$ with sensitivity, specificity, positive and negative predictive values of $100 \%, 60 \%, 71,4 \%$, and $100 \%$ respectively.

A study was done on 102 singleton pregnancies with PPROM but with different gestational age from the current study. The mean gestational age at PPROM was $29 \pm 5.3$ wks (range 14-36.6 wks). The mean AFI in the PPROM and the control groups was $5.8 \pm 3.6 \mathrm{~cm}$ and $13.7 \pm 3.2 \mathrm{~cm}$, respectively ( $\mathrm{P}=0.001)$. An AFI of $<10 \mathrm{~cm}$ had sensitivity $89.2 \%$, specificity $88.5 \%$, positive predictive value $72.2 \%$ and negative predictive value $96 \%$ in the diagnosis of PPROM. ${ }^{12}$

An $\mathrm{AFI} \leq 9 \mathrm{~cm}$ was found in 32 out of 50 patients with confirmed PROM, in 17 out of 50 patients with suspected PROM and in only 4 out of 50patients in the control group. The difference was statistically significant that reported in previous study ${ }^{\mathbf{1 3}}$.

The mean value of AFI was lower in the PROM than in the control group (8.41 \pm $2.91 \mathrm{~cm}$ vs. $9.56 \pm 2.61 \mathrm{~cm}, \mathrm{p}=0.04)$, with a cut-off value of $\leq 7 \mathrm{~cm}$, the sensitivity and specificity of amniotic fluid index to diagnose PROM were $30 \%$ and $91.84 \%$, respectively. The PPV, NPV and over all accuracy were $83.3 \%, 57.3 \%$ and $62 \%$, respectively that was reported in previous study ${ }^{1}$.

On the other hand, it was concluded that there was no significant statistical difference between PROM and control groups regarding AFI. ${ }^{\mathbf{1 4}}$

\section{Vaginal fluid urea}

In the present study, the mean vaginal fluid urea in PROM group was significantly higher than in the control group, $6.5 \pm 2.48$ $\mathrm{mg} / \mathrm{dl}$ vs $3.4 \pm 1.68 \mathrm{mg} / \mathrm{dl}$, respectively $(\mathrm{P}$ $<0.001)$. ROC analysis showed that the best cut-off value was $3 \mathrm{mg} / \mathrm{dl}$. The sensitivity, specificity, PPV and NPV of 
washing vaginal fluid urea were $100 \%$, $80 \%, 83.3 \%$, and $100 \%$, respectively.

These results are consistent with previous study $^{15}$ which reported that, with a cut-off value of $3.5 \mathrm{mg} / \mathrm{dl}$, vaginal fluid urea diagnose PROM with sensitivity, specificity, positive and negative predictive values of $100 \%, 76.5 \%, 70.6 \%$ and $96 \%$, respectively.

Other study ${ }^{16}$ found that urea cut-off value of $3.05 \mathrm{mg} / \mathrm{dl}$ have sensitivity of $85 \%$, specificity $100 \%$, PPV $77 \%$ and NPV of $100 \%$, with a diagnostic accuracy of $90 \%$ of PROM.

In another study, vaginal fluid prolactin, $\beta$ hCG, urea, and creatinine, were studied 2 groups, 80 confirmed PROM patients and 80 controls. ${ }^{10}$ All the four markers were significantly higher in the patients with PROM in comparison to those without PROM $(\mathrm{P}<0.001)$, with a cut-off level of $3.5 \mathrm{mg} / \mathrm{dl}$ for urea, the sensitivity, specificity, positive and negative predictive values to diagnose PROM were $79.7 \%$, $82.5 \%, 81.8 \%$ and $80.4 \%$. They reported less diagnostic value of urea for detecting PROM, because of the difference in laboratory method analysis and cut-off points. ${ }^{10}$
Other studies used different cut-off levels with different results. It was found that the mean vaginal fluid urea levels in definite, suspected and control groups were $34.6 \pm 5.3 \mathrm{mg} / \mathrm{dl}, 2.4 \pm 5.3 \mathrm{mg} / \mathrm{dl}$ and $1.3 \pm 6.2$ $\mathrm{mg} / \mathrm{dl}$, respectively $(\mathrm{P}<0.01)$. With high cutoff value of $12 \mathrm{mg} / \mathrm{dl}$, the sensitivity, specificity, positive and negative predictive values were all $100 \%$. $^{\mathbf{1 4}}$

A cut-off value of urea in vaginal fluid as $10 \mathrm{mg} / \mathrm{dl}$ was used by some researchers, the sensitivity, specificity, positive and negative predictive values in diagnosis of PROM were $26.7 \%, 100 \%, 57.7 \%$ and $100 \%$, respectively. ${ }^{17}$

It was reported by some colleague that the mean vaginal fluid urea levels in confirmed PROM, suspected and control groups were $13.77 \pm 5.41 \mathrm{mg} / \mathrm{dl}, 4.71 \pm 3.64 \mathrm{mg} / \mathrm{dl}$ and $5.13 \pm 5.97 \mathrm{mg} / \mathrm{dl}$, respectively $(\mathrm{P}<0.001)$. The cut-off value of washing vaginal fluid urea was $6 \mathrm{mg} / \mathrm{dl}$ with sensitivity, specificity, positive and negative predictive values of $90 \%, 79 \%, 83 \%$ and $87.5 \% .^{18}$

A study was conducted on 200 patients of which half were controls and other half were confirmed PPROM cases, with cut-off level of $6.7 \mathrm{mg} / \mathrm{dl}$ for urea, the sensitivity, specificity, positive and negative predictive 
values to diagnose PPROM were $88 \%$, $91 \%, 90.7 \%$ and $88.3 \% .^{19}$

\section{Vaginal fluid creatinine}

In the present study, the mean vaginal fluid creatinine in PROM group was significantly higher than in the control group, $0.35 \pm 0.12 \mathrm{mg} / \mathrm{dl}$ vs $0.16 \pm 0.08$ $\mathrm{mg} / \mathrm{dl}$, respectively $(\mathrm{P}<0.001)$. ROC analysis showed that the best cut-off value was $0.2 \mathrm{mg} / \mathrm{dl}$. The sensitivity, specificity, PPV and NPV of washing vaginal fluid creatinine were $100 \%, 84 \%, 86.2 \%$ and $100 \%$ respectively.

The optimal cut-off with best sensitivity, specificity, positive and negative predictive values differ from different studies. The cut-off value ranged from $0.12 \mathrm{mg} / \mathrm{dl}$ to $1.05 \mathrm{mg} / \mathrm{dl}$. One study showed 100\% sensitivity, specificity, positive and negative predictive values ${ }^{20}$. Another study proved a cut-off value of $0.12 \mathrm{mg} / \mathrm{dl}$. In a third study, at cut-off value was detected to be $0.45 \mathrm{mg} / \mathrm{dl}^{18}$ while the cut-off value was declared to be $0.6 \mathrm{mg} / \mathrm{dl}$ in another different research ${ }^{14}$

Other studies showed reasonable sensitivity, specificity, positive and negative predictive values above $80 \%$ or
$90 \%$ as the study ${ }^{21}$ at cut-off value of 1 $\mathrm{mg} / \mathrm{dl}$, other study ${ }^{2}$ at cut-off value of 0.5 $\mathrm{mg} / \mathrm{dl}$, others ${ }^{22}$ at cut-off value of 0.14 $\mathrm{mg} / \mathrm{dl}$, also the study ${ }^{\mathbf{1 6}}$ at cut-off value of $1.05 \mathrm{mg} / \mathrm{dl}$ and $\mathbf{L i}$ - Chang ${ }^{23}$ at cut-off value of 0.95 .

\section{Conclusion}

Detection of vaginal fluid urea and creatinine to diagnose PROM is a simple, reliable and rapid test with high sensitivity, specificity, PPV, NPV.

\section{References}

1. Begum J, Samal SK, Ghose S, and Niranjan G (2017) : Vaginal fluid urea and creatinine in the diagnosis of premature rupture of membranes in resource limited community settings, Journal of family \& reproductive health 11(1) 43-49.

2. Benedetto C, Tibaldi C, Marozio L, Marini S, Masuelli G, Pelissetto S, et al (2004) : Cervicovaginal infections during pregnancy: epidemiological and microbiological aspects, The Journal of Maternal-Fetal \& Neonatal Medicine 16(2) 9-12.

3. Zanjani MS, and Haghighi L (2012) : Vaginal fluid creatinine for the detection of premature rupture of membranes, Journal of Obstetrics and Gynaecology Research 38(3) 505-508.

4. American College of Obstetricians and Gynecologists' Committee on Practice BulletinsObstetrics. ACOG Practice Bulletin No. 80 (2007) : premature rupture of membranes. Clinical 
Benha medical journal Vol. 37, Special issue (surgery), 2020

management guidelines for obstetriciangynecologists, ObstetGynecol 109(4) 1007-1019.

5. Kariman N, Toloui H, Azarhoush R, AlaviMajd H, and Jan-nesari S (2010) : Diagnostic values of urea and creatinine values of cervico vaginal discharges in determining of premature rupture of membranes, Pajouhesh Dar Pezeshki 33 222-227.

6. Park JS, Lee SE, and Norwitz ER (2007) : Noninvasive testing for rupture of the fetal membranes, US Obstet Gynecol 1 13-16

7. El-Messidi A, and Cameron A (2010) : Diagnosis of premature rupture of membranes: inspiration from the past and insights for the future, Journal of Obstetrics and Gynaecology Canada 32(6) 561-569.

8. Doret M, Cartier R, Miribel J, Massardier J, Massoud M, Bordes A, et al (2013) : Premature preterm rupture of the membrane diagnosis in early pregnancy: PAMG-1 and IGFBP-1 detection in amniotic fluid with biochemical tests, Clinical Biochemistry 46(18) 1816-1819.

9. Palacio M, Kühnert M, Berger R, Larios CL, and Marcellin L (2014) : Meta-analysis of studies on biochemical marker tests for the diagnosis of premature rupture of membranes: comparison of performance indexes, BMC pregnancy and childbirth 14(183) 1-12

10. Ghasemi M, Jaami R, Alleyassin A, and Ansarimoghaddam A (2016) : The value of urea, creatinine, prolactin, and beta sub-unit of human chorionic gonadotropin of vaginal fluid in the diagnosis of premature preterm rupture of membranes in pregnancy, Turkish Journal of Obstetrics and Gynecology 13(2) 62-66.

11. Caughey AB, Robinson JN, and Norwitz ER (2008) : Contemporary diagnosis and management of preterm premature rupture of membranes, Reviews in obstetrics and gynecology 1(1) 11-22.

12. Weissmann-Brenner A, O'Reilly-Green C, Ferber A, and Divon MY (2009) :Values of amniotic fluid index in cases of preterm premature rupture of membranes, Journal of perinatal medicine 37(3) 232-235.

13. Mohamed RS, Rashed RM, Hassanein RA, Oun A, and Abdel-Maksoud SM (2015) :Vaginal fluid creatinine versus human chorionic gonadotropin for diagnosis of premature rupture of membranes, J Am Sci 11(01) 33-39.

14. Kafali H, and Öksüzler C (2007) :Vaginal fluid urea and creatinine in diagnosis of premature rupture of membranes, Archives of gynecology and obstetrics 275(3) 157-160.

15. Tavana Z, Hamedi B, Zolghadri J, and Madadi G (2010) :The evaluation of diagnostic role of vaginal fluid urea, creatinine and B-HCG level for detection of premature rupture of membrane, The Internet Journal of Gynecology and Obstetrics 15(1) 1-6.

16. HANFY A (2010) :Urea and Creatinine Levels of Washed Vaginal Fluid a Gold Standard Test to Detect PROM, The Medical Journal of Cairo University 78(2).

17. Tigli A, Kurt S, and Kopuz A (2014) :The roles of beta-human chorionic gonadotropin, creatinine and urea in vaginal washing fluid in the diagnosis of premature rupture of membranes, Perinatal Journal 22(3) 133-137.

18. Kariman N, Afrakhte M, Hedayati M, Fallahian M, and Majd HA (2013) : Diagnosis of premature rupture of membranes by assessment of urea and 
creatinine in vaginal washing fluid, Iranian journal of reproductive medicine 11(2) 93-100.

19. Gezer C, Ekin A, Golbasi C, Kocahakimoglu C, Bozkurt U, Dogan A, et al (2017) : Use of urea and creatinine levels in vaginal fluid for the diagnosis of preterm premature rupture of membranes and delivery interval after membrane rupture, The Journal of Maternal-Fetal \& Neonatal Medicine 30(7) 772-778.

20. Gurbuz A, Karateke A, and Kabaca C (2004) :Vaginal fluid creatinine in premature rupture of membranes, International journal of gynaecology and obstetrics 85(3) 270-271.
21. Cortez FVD, and Ocampo-Tapia MS (2018) :Vaginal fluid creatinine for the detection of prelabor rupture of membranes, Philippine Journal of Obtetrics and Gynecology 42(6) 16-25.

22. Sekhavat L, Firouzabadi RD, and Mojiri P (2012) :Practicability of vaginal washing fluid creatinine level in detecting premature rupture of membranes, Archives of gynecology and obstetrics 286(1) 25-28.

23. Li H-Y, and Chang T-S (2000) :Vaginal fluid creatinine, human chorionic gonadotropin and alpha-fetoprotein levels for detecting premature rupture of membranes, Zhonghua yix ue za zhi= Chinese medical journal; Free China ed 63(9) 686690.

To cite this article: Khaled M. slama, Ahmed Salah El din, Aymen S. Elgohary, Basma M. Mostafa Evaluation of Vaginal Fluid Urea and Creatinine as Biomarkers of Preterm Premature Rupture of Membranes. BMFJ 2020;37 (surgical issue): 106-118. DOI: 10.21608/bmfj.2020.44080.1320 